\title{
Auranofin induces apoptosis and necrosis in HeLa cells via oxidative stress and glutathione depletion
}

\author{
BO RA YOU, HYE RIM SHIN, BO RAM HAN, SUHN HEE KIM and WOO HYUN PARK \\ Department of Physiology, Medical School, Research Institute for Endocrine Sciences, \\ Chonbuk National University, Jeonju, Jeollabuk 561-180, Republic of Korea
}

Received December 21, 2013; Accepted June 24, 2014

DOI: $10.3892 / \mathrm{mmr} .2014 .2830$

\begin{abstract}
Auranofin (Au), an inhibitor of thioredoxin reductase, is a known anti-cancer drug. In the present study, the anti-growth effect of $\mathrm{Au}$ on HeLa cervical cancer cells was examined in association with levels of reactive oxygen species (ROS) and glutathione (GSH). Au inhibited the growth of HeLa cells with an $\mathrm{IC}_{50}$ of $\sim 2 \mu \mathrm{M}$ at $24 \mathrm{~h}$. This agent induced apoptosis and necrosis, accompanied by the cleavage of poly (ADP-ribose) polymerase and loss of mitochondrial membrane potential. The pan-caspase inhibitor, benzyloxycarbonyl-Val-Ala-Asp-fluoromethylketone, prevented apoptotic cell death and each of the assessed caspase inhibitors inhibited necrotic cell death induced by Au. With respect to the levels of ROS and GSH, Au increased intracellular $\mathrm{O}_{2}{ }^{-}$in the HeLa cells and induced GSH depletion. The pan-caspase inhibitor reduced the levels of $\mathrm{O}_{2}{ }^{--}$and GSH depletion in Au-treated HeLa cells. The antioxidant, $\mathrm{N}$-acetyl cysteine, not only attenuated apoptosis and necrosis in the Au-treated HeLa cells, but also decreased the levels of $\mathrm{O}_{2}{ }^{-}$and GSH depletion in the
\end{abstract}

Correspondence to: Professor Woo Hyun Park, Department of Physiology, Medical School, Chonbuk National University, San 2-20 Geumam-dong, Deokjin-gu, Jeonju, Jeollabuk 561-180, Republic of Korea

E-mail: parkwh71@chonbuk.ac.kr

Abbreviations: Au, auranofin; ROS, reactive oxygen species; $\operatorname{MMP}\left(\Delta \Psi_{\mathrm{m}}\right)$, mitochondrial membrane potential; FBS, fetal bovine serum; MTT, 3-(4,5-dimethylthiazol-2-yl)-2,5-diphenyltetrazolium bromide; PI, propidium iodide; FITC, fluorescein isothiocyanate; Z-VAD-FMK, benzyloxycarbonyl-Val-Ala-Asp-fluoromethylketone; Z-DEVD-FMK, benzyloxycarbonyl-Asp-Glu-Thr-Asp-fluoro methylketone; Z-IETD-FMK, benzyloxycarbonyl-Ile-Glu-Thr -Asp-fluoromethylketone; Z-LEHD-FMK, benzyloxycarbonyl-LeuGlu-His-Asp-fluoromethylketone; LDH, lactate dehydrogenase; NAC, N-acetyl cysteine; BSO, L-buthionine sulfoximine; DHE, dihydroethidium; GSH, glutathione; CMFDA, 5-chloromethylfluorescein diacetate; Trx, thioredoxin; TrxR, thioredoxin reductase

Key words: auranofin, apoptosis, necrosis, reactive oxygen species, glutathione cells. By contrast, L-buthionine sulfoximine, a GSH synthesis inhibitor, intensified cell death $\mathrm{O}_{2}{ }^{--}$and $\mathrm{GSH}$ depletion in the Au-treated HeLa cells. In conclusion, Au induced apoptosis and necrosis in HeLa cells via the induction of oxidative stress and the depletion of GSH.

\section{Introduction}

The thioredoxin (Trx) system, consisting of Trx, Trx reductase (TrxR) and nicotinamide adenine dinucleotide phosphate (NADPH), is a major disulfide reductase system, which is important in cellular redox balance (1). While Trx1 and TrxR1 are usually localized in the cytoplasm, Trx 2 and TrxR2 are located in the mitochondria (2). Trx is typically a small, $12 \mathrm{kDa}$ protein reductase with two active site cysteine residues, 32 and 35. It exists either as a dithiol in the reduced form or as a disulfide in the oxidized form. When Trx is oxidized, it is reduced back to the dithiol by the NADPH-dependent selenoprotein, TrxR (3). TrxR not only controls oxidative stress via Trx, but also affects a number of cellular functions, including DNA repair, cell proliferation and angiogenesis (4). Trx and TrxR1 are overexpressed in numerous cancer cells, including lung cancer (5-7). Therefore, modulation of the Trx system is a promising target for cancer therapy. It has been reported that the inhibition of TrxR increases the sensitivity of anti-cancer drugs in various cancer cells, including lung and colon cancer $(8,9)$.

Auranofin $(\mathrm{Au})$, an inhibitor of TrxR, has an anti-inflammatory effect (10) and is used to treat rheumatoid arthritis (11). It has been reported that $\mathrm{Au}$ suppresses the immune response in dendritic cells and macrophages by inhibiting the major histocompatibility complex-restricted antigen presentation and pro-inflammatory cytokines, including interleukin-1 $\beta(12,13)$. However, several studies have suggested that Au induces apoptosis in breast cancer and leukemia cells $(14,15)$. This agent also leads to mitochondrial permeability transition and the generation of reactive oxygen species (ROS) $(16,17)$.

Cervical cancer is a major cause of mortality in females worldwide and its occurrence results from multiple factors, including papillomaviruses, cigarette smoking and nutrition (18). Oxidative stress can also contribute to the carcinogenesis of cervical cancer. Furthermore, the level of TrxR2 is increased in dysplastic and neoplastic cervical tissues (19). Previous studies have suggested that $\mathrm{Au}$ is a good candidate 
anti-cancer drug in various cancer cells (20-22). However, the cellular effect of $\mathrm{Au}$ in cervical cancer cells remains to be elucidated. Therefore, in the present study, the effects of Au on cell growth and cell death in human cervical HeLa cells was examined in association with changes in the levels of ROS and glutathione (GSH).

\section{Materials and methods}

Cell culture. Human cervical adenocarcinoma HeLa cells from the American Type Culture Collection (Manassas, VA, USA) were cultured in RPMI-1640 (Sigma-Aldrich, St. Louis, MO, USA). This medium was supplemented with $10 \%$ fetal bovine serum (Sigma-Aldrich) and $1 \%$ penicillin-streptomycin (Gibco-BRL, Grand Island, NY, USA). The HeLa cells were maintained in a humidified incubator containing $5 \% \mathrm{CO}_{2}$ at $37^{\circ} \mathrm{C}$. The cells were routinely grown in $100 \mathrm{~mm}$ plastic tissue culture dishes (Nunc, Roskilde, Denmark) and harvested with a solution of trypsin-EDTA (Gibco-BRL).

Reagents. Au was purchased from Santa Cruz Biotechnology, Inc. (Santa Cruz, CA, USA) and was dissolved in dimethyl sulfoxide(DMSO; Sigma-Aldrich) at $10 \mathrm{mM}$ as a stock solution. The pan-caspase inhibitor benzyloxycarbonyl-Val-Ala-Asp-fluoromethylketone (Z-VAD-FMK), caspase-3 inhibitor benzyloxycarbonyl-Asp-Glu-Val-Asp-fluoromethylketone (Z-DEVD-FMK), caspase-8 inhibitor benzyloxycarbonyl-Ile-Glu-Thr-Asp-fluoromethylketone (Z-IETD-FMK) and the caspase-9 inhibitor benzyloxycarbonyl-Leu-Glu-His-Asp-fluoromethylketone (Z-LEHD-FMK) were obtained from R\&D Systems, Inc. (Minneapolis, MN, USA) and were dissolved in DMSO at $10 \mathrm{mM}$ to serve as stock solutions. N-acetyl cysteine (NAC) and L-buthionine sulfoximine (BSO), obtained from Sigma-Aldrich, were dissolved in buffer (20 mM HEPES at $\mathrm{pH}$ 7.0) and water at $100 \mathrm{mM}$ as a stock solution, respectively. Cells were pretreated with $15 \mu \mathrm{M}$ caspase inhibitors, $2 \mathrm{mM}$ NAC or $10 \mu \mathrm{M}$ BSO for $1 \mathrm{~h}$ prior to Au treatment. DMSO $(0.01 \%)$ was used as a control vehicle and it did not affect cell growth or cell death.

Cell growthassay. To determine the effect of Au on cell growth, the absorbance of 3-(4,5-dimethylthiazol-2-yl)-2,5-diphenyltetrazolium bromide (MTT; Sigma-Aldrich) was measured in living cells, as described previously (23). Breifly, $5 \times 10^{3}$ cells were seeded in 96-well microtiter plates (Nunc). After exposure to the indicated doses of $\mathrm{Au}$ with or without $15 \mu \mathrm{M}$ of each caspase inhibitor, $2 \mathrm{mM}$ NAC or $10 \mu \mathrm{M}$ BSO for the designated times, MTT solution (20 $\mu \mathrm{l}: 2 \mathrm{mg} / \mathrm{ml}$ in phosphate buffered saline; PBS) was added to each well of the 96 -well plates. The plates were incubated for $3 \mathrm{~h}$ at $37^{\circ} \mathrm{C}$. Medium was removed from the plates by pipetting and $200 \mu 1 \mathrm{DMSO}$ was added to each well for solubilizing the formazan crystals. The optical density was measured at $570 \mathrm{~nm}$ using a microplate reader $\left(\right.$ Synergy ${ }^{\mathrm{TM}}$ 2; BioTek Instruments Inc., Winooski, VT, USA).

Sub-G1 cell analysis. Sub-G1 cell analysis was determined by propidium iodide (PI; Ex/Em=488/617 nm; Sigma-Aldrich) staining, as described previously (24). In brief, $1 \times 10^{6}$ cells were incubated in a $60 \mathrm{~mm}$ culture dish (Nunc) with the designated doses of $\mathrm{Au}$ for $24 \mathrm{~h}$. Cells were washed again with PBS and incubated with PI $(10 \mathrm{mg} / \mathrm{ml})$ with simultaneous RNase treatment at $37^{\circ} \mathrm{C}$ for $30 \mathrm{~min}$. Cellular DNA content was measured using a FACStar flow cytometer (Becton Dickinson, Franklin Lakes, NJ, USA) and analyzed using Lysis II and Cellfit software (Becton Dickinson).

Annexin V-fluorescein isothiocyanate (FITC)/PI staining for cell death detection. To determine apoptotic cell death, cells were stained with annexin V-FITC (Invitrogen Life Technologies, Carlsbad, CA, USA; Ex/Em=488/519 nm), as described previously (24). In brief, $1 \times 10^{6}$ cells in a $60 \mathrm{~mm}$ culture dish (Nunc) were incubated with the designated doses of $\mathrm{Au}$, with or without $15 \mu \mathrm{M}$ of each caspase inhibitor, $2 \mathrm{mM}$ NAC or $10 \mu \mathrm{M}$ BSO for $24 \mathrm{~h}$. Cells were washed twice with cold PBS and then resuspended in $500 \mu \mathrm{l}$ binding buffer (10 mM HEPES/sodium hydroxide pH 7.4, $140 \mathrm{mM}$ sodium chloride and $\left.2.5 \mathrm{mM} \mathrm{CaCl}_{2}\right)$ at a concentration of $1 \times 10^{6}$ cells $/ \mathrm{ml}$. Annexin V-FITC $(5 \mu \mathrm{l})$ and PI $(1 \mu \mathrm{g} / \mathrm{ml})$ were then added and the cells were analyzed with a FACStar flow cytometer (Becton Dickinson).

Western blot analysis. The expression of proteins was evaluated using western blot analysis, as previously described (25). In brief, $1 \times 10^{6}$ cells were incubated in a $60 \mathrm{~mm}$ culture dish (Nunc) with the designated doses of $\mathrm{Au}$ for $24 \mathrm{~h}$. The cells were then washed in PBS and suspended in five volumes of lysis buffer [20 mM HEPES, pH 7.9, $20 \%$ glycerol, $200 \mathrm{mM}$ potassium chloride, $0.5 \mathrm{mM}$ EDTA, 0.5\% NP40, $0.5 \mathrm{mM}$ DTT and $1 \%$ protease inhibitor cocktail (SigmaAldrich)]. The concentration of supernatant proteins was determined using the Bradford method. Supernatant samples containing $30 \mathrm{mg}$ total protein were resolved by 7.5 or $12.5 \%$ SDS-PAGE gels depending on the sizes of target proteins, transferred onto Immobilon-P polyvinylidene difluoride membranes (Millipore, Billerica, MA, USA) by electroblotting and then probed with anti-poly ADP ribose polymerase, monoclonal rabbit anti-B-cell lymphoma $2(\mathrm{Bcl}-2)$, polyclonal rabbit anti-BCL2-associated $\mathrm{X}$ protein (Bax) purchased from Cell signaling Technology, Inc. (Danvers, MA, USA), polyclonal rabbit anti-Trx1, monoclonal mouse anti-TrxR1, polyclonal rabbit anti-Trx2, polyclonal goat anti-TrxR2 and monoclonal goat anti- $\beta$-actin antibodies (Santa Cruz Biotechnology, Inc.). Membranes were incubated with horseradish peroxidase-conjugated secondary antibodies and blots were developed using an ECL kit (Amersham, Arlington Heights, IL, USA).

Measurement of mitochondrial membrane potentisal (MMP, $\left.\Delta \Psi_{m}\right)$. To measure MMP levels, a rhodamine 123 fluorescent dye (Sigma-Aldrich; Ex/Em=485/535 nm) was used as described previously $(24,26)$. In brief, $1 \times 10^{6}$ cells in a $60 \mathrm{~mm}$ culture dish (Nunc) were incubated with the designated doses of $\mathrm{Au}$ for $24 \mathrm{~h}$. Cells were washed twice with PBS and incubated with the rhodamine $123(0.1 \mathrm{mg} / \mathrm{ml})$ at $37^{\circ} \mathrm{C}$ for $30 \mathrm{~min}$. Rhodamine 123 staining intensity was determined using a FACStar flow cytometer. Rhodamine 123 negative cells indicated a MMP loss in cells. 
Lactate dehydrogenase ( $L D H)$ assay for the detection of necrosis. Necrosis in the cells treated with Au was evaluated using an LDH kit (Sigma-Aldrich). In brief, $1 \times 10^{6}$ cells were incubated in a $60 \mathrm{~mm}$ culture dish (Nunc) with the indicated doses of $\mathrm{Au}$, with or without $15 \mu \mathrm{M}$ caspase inhibitors, $2 \mathrm{mM}$ $\mathrm{NAC}$ or $10 \mu \mathrm{M}$ BSO for $24 \mathrm{~h}$. Following treatment, the culture media were collected and centrifuged for $5 \mathrm{~min}$ at $211 \mathrm{x} \mathrm{g}$. Media supernatant (50 $\mu 1)$ was added to a fresh 96-well plate with LDH assay reagent and incubated at room temperature for $30 \mathrm{~min}$. The absorbance values were measured at $490 \mathrm{~nm}$ using a microplate reader. LDH release was expressed as the percentage of extracellular LDH activity compared with the control cells.

Detection of intracellular $\mathrm{O}_{2}{ }^{--}$levels. The level of intracellular $\mathrm{O}_{2}{ }^{-}$was specifically detected using dihydroethidium (DHE; Ex/Em=510/580 nm; Invitrogen Life Technologies). In brief, $1 \times 10^{6}$ cells were incubated in a $60 \mathrm{~mm}$ culture dish (Nunc) with the designated doses of $\mathrm{Au}$, with or without $15 \mu \mathrm{M}$ caspase inhibitors, $2 \mathrm{mM}$ NAC or $10 \mu \mathrm{M} \mathrm{BSO}$ for $24 \mathrm{~h}$. Cells were then washed in PBS and incubated with $20 \mu \mathrm{M}$ DHE at $37^{\circ} \mathrm{C}$ for $30 \mathrm{~min}$. DHE fluorescence was detected using a FACStar flow cytometer (Becton Dickinson). Levels of mitochondrial $\mathrm{O}_{2}{ }^{-}$are expressed as mean fluorescence intensity, which was calculated using CellQuest software (Becton Dickinson).

Detection of intracellular GSH. Levels of cellular GSH were analyzed using a 5-chloromethylfluorescein diacetate dye (CMFDA; Ex/Em=522/595 nm; Invitrogen Life Technologies), as previously described (27). In brief, $1 \times 10^{6}$ cells were incubated in a $60 \mathrm{~mm}$ culture dish (Nunc) with the designated doses of $\mathrm{Au}$, with or without $15 \mu \mathrm{M}$ caspase inhibitors, $2 \mathrm{mM} \mathrm{NAC}$ or $10 \mu \mathrm{M}$ BSO for $24 \mathrm{~h}$. After washing with PBS, the cells were incubated with $5 \mu \mathrm{M}$ CMFDA at $37^{\circ} \mathrm{C}$ for $30 \mathrm{~min}$. The intensity of 5-chloromethylfluorescein (CMF) fluorescence was determined using a FACStar flow cytometer. The percentage of negative CMF cells indicated GSH depletion of cells.

Detection of TrxR activity. The activity of TrxR was assessed using the Thioredoxin Reductase assay kit according to the manufacturer's instructions (Sigma-Aldrich). In brief, $1 \times 10^{6}$ cells were incubated in a $60 \mathrm{~mm}$ culture dish (Nunc) with the indicated doses of Au for $24 \mathrm{~h}$. The cells were then washed in PBS and suspended in five volumes of lysis buffer (R\&D systems, Inc.). Protein concentrations were determined using the Bradford method. Supernatant samples containing $30 \mu \mathrm{g}$ total protein were used for the determination of TrxR activity. These were added to each well in 96-well microtiter plates (Nunc) with 5,5'-dithiobis (2-nitrobenzoic) acid at $25^{\circ} \mathrm{C}$ for $1 \mathrm{~h}$. The optical density of each well was measured at $412 \mathrm{~nm}$ using a microplate reader $\left(\right.$ Synergy $^{\mathrm{TM}} 2$, BioTek $^{\circledR}$ Instruments Inc.).

Statistical analysis. The results are expressed as the mean of at least three independent experiments (mean \pm standard deviation). Data were analyzed using Instat software (GraphPad Prism4; GraphPad Software, San Diego, CA, USA). Student's t-test or one-way analysis of variance with
A

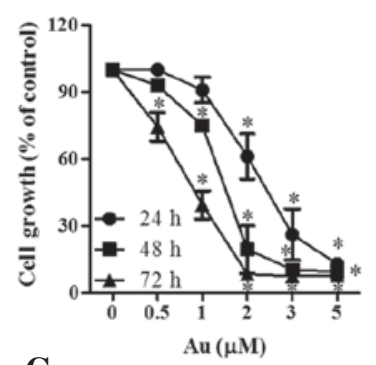

C

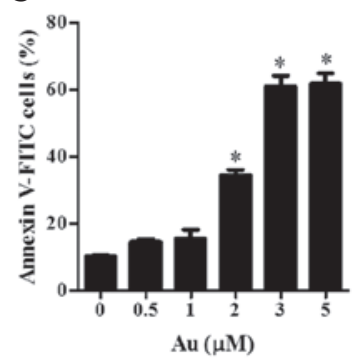

$\mathbf{E}$

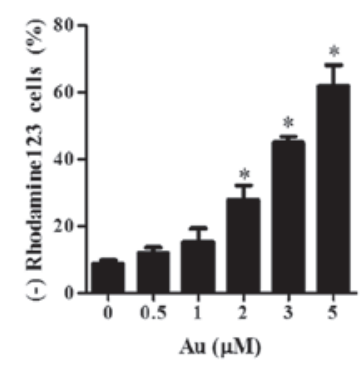

B

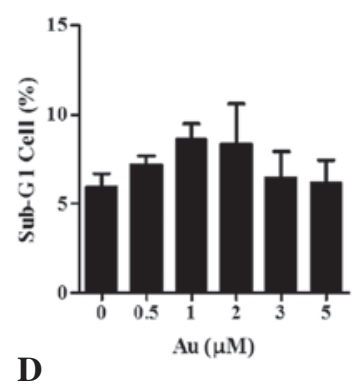

D

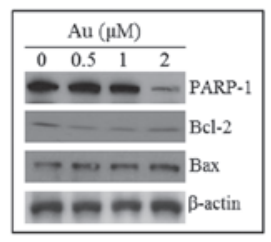

F

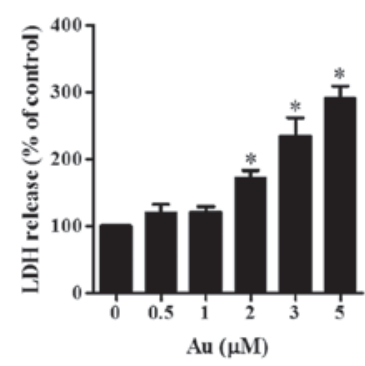

Figure 1. Effects of Au on cell growth and death in HeLa cells. Exponentially growing cells were treated with the designated concentrations of $\mathrm{Au}$ for the indicated durations. (A) Graph of the cellular growth changes in HeLa cells at 24, 48 and $72 \mathrm{~h}$ as assessed by 3-(4,5-dimethylthiazol-2-yl)-2,5-diphenyltetrazolium bromide assays. (B and C) Graphs of the percentages of sub-G1 cells and annexin V-positive cells at $24 \mathrm{~h}$, respectively. (D) Western blotting results showing the levels of PARP,-1 Bcl-2, Bax and $\beta$-actin. (E and F) Graphs of the percentages of rhodamine 123-negative (loss of mitochondrial membrane potential) cells and release of $\mathrm{LDH}$ compared with the control cells at $24 \mathrm{~h} .{ }^{*} \mathrm{P}<0.05$, compared with the control group. Au, auranofin; LDH, lactate dehydrogenase; FITC, fluorescein isothiocyanate; PARP-1, poly ADP-ribose polymerase 1; Bcl-2, B-cell lymphoma-2; Bax, BCL2-associated $\mathrm{X}$ protein.

post hoc analysis using Tukey's multiple comparison test were used for parametric data. $\mathrm{P}<0.05$ was considered to indicate a statistically significant difference.

\section{Results}

Effects of Au on cell growth, cell death and MMP in HeLa cells. Initially, the effect of $\mathrm{Au}$ on the growth inhibition of HeLa cells was examined using MTT assays. Following exposure to Au for 24, 48 and $72 \mathrm{~h}$, the growth of HeLa cells dose and time-dependently decreased with an $\mathrm{IC}_{50}$ of $\sim 2,1.5$ and $1 \mu \mathrm{M}$ at 24, 48 and $72 \mathrm{~h}$, respectively (Fig. 1A).

As shown in Fig. 1B, Au did not affect the proportion of sub-G1 cells in the HeLa cells at $24 \mathrm{~h}$. However, when HeLa cells were stained with annexin V-FITC to evaluate the induction of apoptosis, the percentages of annexin 
A

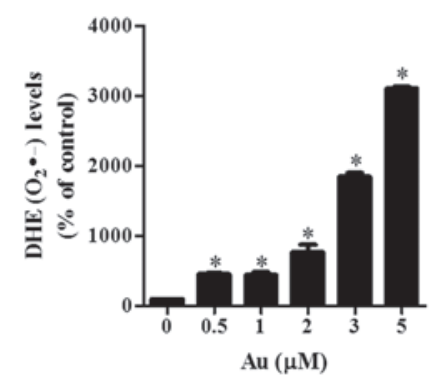

B

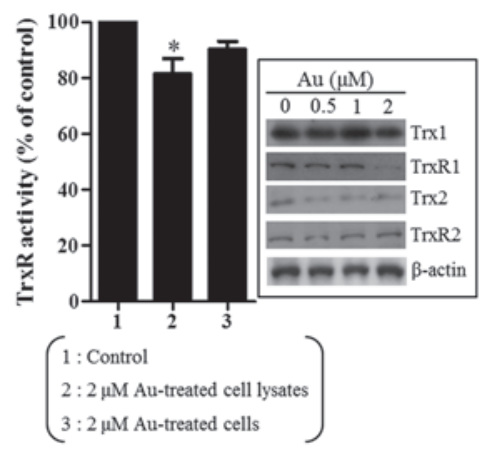

C

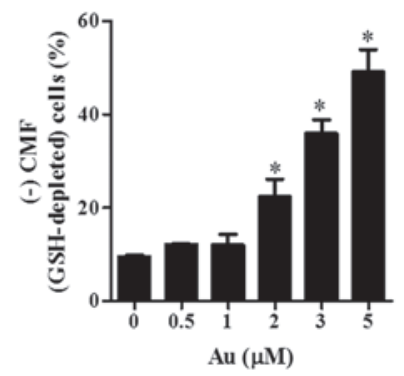

Figure 2. Effects of $\mathrm{Au}$ on the levels of intracellular $\mathrm{O}_{2}{ }^{--}$and $\mathrm{GSH}$ in HeLa cells. Exponentially growing cells were treated with the designated concentration of $\mathrm{Au}$ for $24 \mathrm{~h}$. (A) Graph showing the levels of DHE $\left(\mathrm{O}_{2}{ }^{\circ}\right)$ compared with those in the control cells. (B) Graph showing the activity of TrxR in HeLa cells. The inside figures demonstrate the levels of Trx1, TrxR1, Trx2, TrxR2 and $\beta$-actin. (C) Graph of the percentage of (-) CMF (GSH-depleted) cells in HeLa cells. ${ }^{*} \mathrm{P}<0.05$, compared with the control group. Au, auranofin; DHE, dihydroethidium; GSH, glutathione; CMF, 5-chloromethylfluorescein; Trx, thioredoxin; TrxR, thioredoxin reductase; CMF, 5-chloromethylfluorescein.

V-staining cells increased in a dose-dependent manner in Au-treated HeLa cells (Fig. 1C). This agent decreased the expression of PARP-1 and Bcl-2, whereas it increased the expression of Bax (Fig. 1D). In addition, Au triggered the loss of MMP and increased the release of $\mathrm{LDH}$ in HeLa cells at $24 \mathrm{~h}$ in a dose-dependent manner (Fig. 1E and F). These results indicated that $\mathrm{Au}$ induced necrosis as well as apoptosis in the HeLa cells.

Effects of Au on levels of intracellular $\mathrm{O}_{2}{ }^{--}$and $\mathrm{GSH}$ in $\mathrm{HeLa}$ cells. Alterations in the levels of intracellular $\mathrm{O}_{2}{ }^{-}$and $\mathrm{GSH}$ in Au-treated HeLa cells were also examined. As shown in Fig. 2A, Au significantly increased the levels of intracellular $\mathrm{O}_{2}^{--}$(DHE) in HeLa cells at $24 \mathrm{~h}$. Au, a known inhibitor of TrxR, also decreased the activities of TrxR in HeLa cell lysates and cells (Fig. 2B). In addition, examination of the expression of Trx system-related proteins demonstrated that the levels of TrxR1 and Trx 2 were downregulated by Au (Fig. 2B). Additionally, Au markedly increased the percentage of GSH-depleted cells in HeLa cells at 24 h (Fig. 2C).

Effects of caspase inhibitors on cell death, $\mathrm{O}_{2}{ }^{--}$and GSH levels in Au-treated HeLa cells. To determine which caspases were involved in the death of Au-treated HeLa cells, the effects of caspase inhibitors in those cells were assessed. For this experiment, $2 \mu \mathrm{M}$ Au was selected as a suitable dose to differentiate the level of cell death in the presence or absence of each of the following caspase inhibitors: pan-caspase inhibitor (Z-VAD), caspase-3 inhibitor (Z-DEVD), caspase-8 inhibitor (Z-IELD) and the caspase- 9 inhibitor (Z-LEHD). The concentration of each caspase inhibitor, $15 \mu \mathrm{M}$, was selected as the optimal dose for the present study as it did not significantly affect cell death in the control cells (28). Among the caspase inhibitors, Z-VAD significantly attenuated apoptosis induced by Au in HeLa cells at $24 \mathrm{~h}$ (Fig. 3A). Although Z-DEVD and Z-IETD also partially prevented apoptotic cell death in Au-treated HeLa cells, Z-LEHD did not have an effect (Fig. 3A). Furthermore, all caspase inhibitors, particularly Z-VAD, decreased the release of LDH triggered by $\mathrm{Au}$ in HeLa cells (Fig. 3B). Therefore, a
A

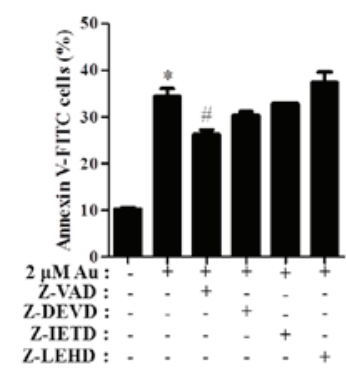

C

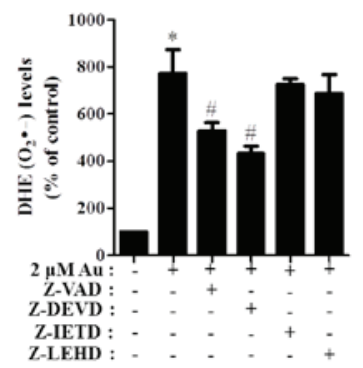

B

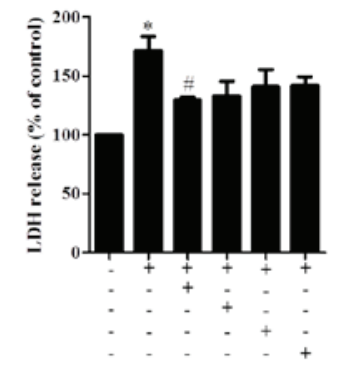

$\mathbf{D}$

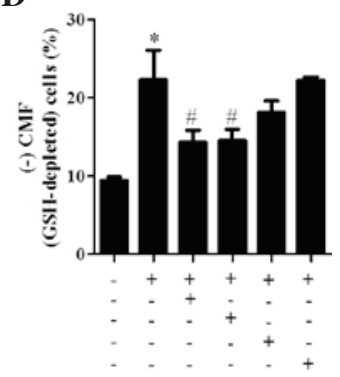

Figure 3. Effects of caspase inhibitors on cell death and levels of $\mathrm{O}_{2}{ }^{-*}$ and GSH in Au-treated HeLa cells. Exponentially growing cells were treated with $2 \mu \mathrm{M} \mathrm{Au}$ and/or $15 \mu \mathrm{M}$ caspase inhibitors for $24 \mathrm{~h}$. (A and B) Graphs of the percentages of annexin $\mathrm{V}$-positive cells and release of $\mathrm{LDH}$, respectively. (C and D) Graphs showing the levels of DHE $\left(\mathrm{O}_{2}{ }^{-*}\right)$ and the percentages of (-) CMF (GSH-depleted) cells in the HeLa cells. ${ }^{*} \mathrm{P}<0.05$, compared with the control group. ${ }^{*} \mathrm{P}<0.05$, compared with cells treated with Au only. Au, auranofin; DHE, dihydroethidium; GSH, glutathione; LDH, lactate dehydrogenase; CMF, 5-chloromethylfluorescein; Z-VAD, benzyloxycarbonyl-Val-Ala-Asp-fluoromethylketone; Z-DEVD, benzyloxycarbonyl-Asp-Glu-Thr-Asp-fluoromethylketone; Z-IETD, benzyloxycarbonyl-Ile-Glu-Thr-Asp-fluoromethylketone; Z-LEHD, benzyloxycarbonyl-Leu-Glu-His-Asp-fluoromethylketone; FITC, fluorescein isothiocyanate.

variety of caspases appeared to be involved in apoptotic and necrotic cell death in Au-treated HeLa cells.

In association with the levels of $\mathrm{O}_{2}{ }^{--}$and GSH, Z-VAD and Z-DEVD significantly reduced levels of $\mathrm{O}_{2}{ }^{--}$(DHE) in HeLa cells treated with $\mathrm{Au}$ and prevented the depletion of GSH in 
A

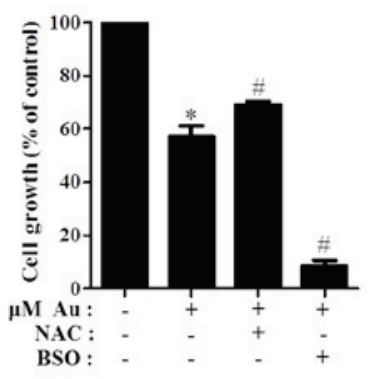

B

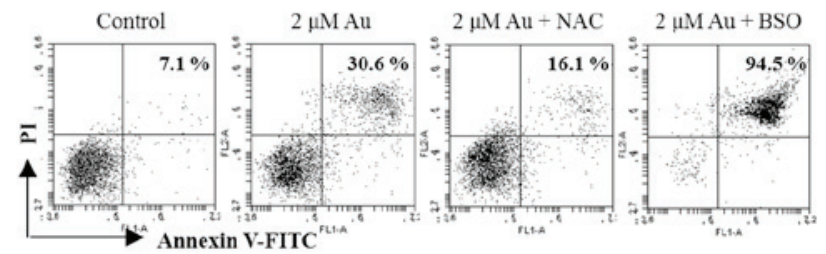

C

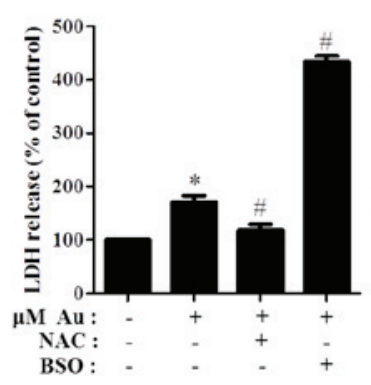

D

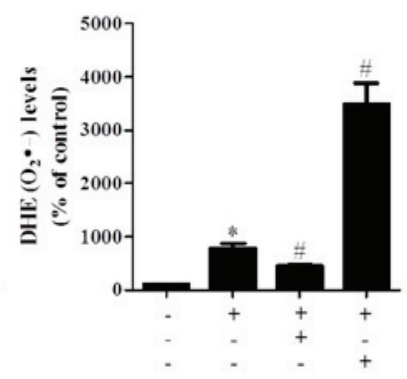

E

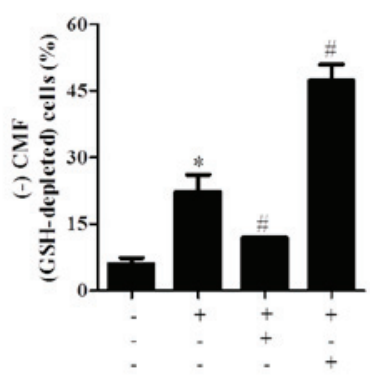

Figure 4. Effects of NAC and BSO on cell growth, cell death, $\mathrm{O}_{2}{ }^{--}$and GSH levels in Au-treated HeLa cells. Exponentially growing cells were treated with $2 \mu \mathrm{M}$ $\mathrm{Au}$ and/or $2 \mathrm{mM}$ NAC or $10 \mu \mathrm{M}$ BSO for $24 \mathrm{~h}$. (A) Graph of cellular growth changes. (B) Annexin V-FITC and PI cells were measured with a FACstar flow cytometer. The numbers in each figure indicate the percentages of annexin V-FITC positive cells regardless of PI negative and positive cells. (C) Graph showing the release of LDH. (D and E) Graphs showing levels of DHE $\left(\mathrm{O}_{2}{ }^{-}\right)$and the percentages of $(-) \mathrm{CMF}(\mathrm{GSH}-\mathrm{depleted})$ cells in the HeLa cells. ${ }^{*} \mathrm{P}<0.05$, compared with the control group. "P<0.05, compared with the cells treated with Au only. Au, Auranofin; NAC, N-acetyl cysteine; BSO, L-buthionine sulfoximine; PI, propidium iodide; LDH, lactate dehydrogenase; DHE, dihydroethidium; CMF, 5-chloromethylfluorescein; GSH, glutathione; FITC, fluorescein isothiocyanate.

those cells (Fig. 3C and D). While Z-IETD prevented depletion of GSH in Au-treated HeLa cells, it did not affect levels of $\mathrm{O}_{2}^{--}$in those cells (Fig 3C and D). Z-LEHD did not result in any alterations in the levels of $\mathrm{O}_{2}{ }^{--}$or GSH (Fig. 3C and D).

Effects of NAC and BSO on cell growth, cell death, $\mathrm{O}_{2}{ }^{--}$and GSH levels in Au-treated HeLa cells. The effects of NAC and BSO on cell growth, cell death and levels of ROS and GSH were then assessed in $2 \mu \mathrm{M} \mathrm{Au}$-treated HeLa cells at $24 \mathrm{~h}$. As shown in Fig. 4A, NAC significantly recovered the inhibition of cell growth induced by Au. NAC also prevented apoptotic cell death and release of $\mathrm{LDH}$ in Au-treated HeLa cells (Fig. 4B and C). However, as an inhibitor of GSH synthesis, BSO enhanced the inhibition of cell growth, apoptosis and the release of LDH induced by $\mathrm{Au}$ in HeLa cells (Fig. 4A-C). In the assessment of whether NAC and BSO affect the levels of $\mathrm{O}_{2}{ }^{--}$and $\mathrm{GSH}$ in Au-treated HeLa cells, NAC attenuated the levels of $\mathrm{O}_{2}{ }^{-}$and the depletion of GSH in these cells (Fig. 4D and E). By contrast, BSO significantly enhanced the levels of $\mathrm{O}_{2}{ }^{--}$and the depletion of GSH induced by Au in HeLa cells (Fig. 4D and E).

\section{Discussion}

In the present study, the anti-cancer effects of $\mathrm{Au}$ on $\mathrm{HeLa}$ cervical cancer cells was investigated in association with the levels of ROS and GSH. Au significantly and efficiently decreased the growth of HeLa cells in a dose and time-dependent manner. When the cell cycle distributions were examined in Au-treated HeLa cells, Au did not induce any specific phase arrest of the cell cycle at $24 \mathrm{~h}$ (data not shown) and did not increase the number of sub-G1 cells in the HeLa cells. However, Au induced cell death via apoptosis, which was accompanied by the cleavage of PARP. This agent also led to loss of MMP in HeLa cells. It has been suggested that a high ratio of Bax to Bcl-2 can cause the collapse of MMP (29). Similarly, apoptosis and loss of MMP caused by Au were accompanied by the downregulation of Bcl-2 and the upregulation of Bax. Furthermore, this drug also induced necrosis, which was supported by the release of LDH. Therefore, these results suggested that $\mathrm{Au}$ induced apoptotic and necrotic cell death in HeLa cells.

In determining which caspases were involved in cell death in Au-treated HeLa cells, Z-VAD significantly prevented apoptosis and necrosis induced by Au. Z-DEVD and Z-IETD also rescued certain cells from $\mathrm{Au}$-induced apoptotic and necrotic cell death. Although Z-LEHD did not significantly prevent apoptosis in the Au-treated HeLa cells, it inhibited the necrosis induced by Au. Therefore, apoptotic cell death caused by $\mathrm{Au}$ was mediated by the extrinsic apoptotic pathway of caspase- 8 and the intrinsic apoptotic pathway of caspase-9. In addition, the activation of various caspases was tightly involved in necrosis in the Au-treated HeLa cells, which supported the hypothesis that caspase activation contributes to necrotic cell death $(30,31)$.

$\mathrm{Au}$, as an inhibitor of TrxR, can affect the redox status of cells. It is reported that Au generates ROS in solid tumor and leukemia cells and induces apoptosis in these cells $(14,32)$. Similarly, levels of intracellular $\mathrm{O}_{2}{ }^{--}$were markedly increased in the Au-treated HeLa cells. The pan-caspase inhibitor, 
Z-VAD, which demonstrated anti-apoptotic effects, appeared to decrease the levels of $\mathrm{O}_{2}{ }^{--}$in the cells. These results suggested that alterations in the levels of intracellular $\mathrm{O}_{2}^{-{ }^{-}}$were closely associated with apoptotic and necrotic cell death caused by Au. Furthermore, NAC attenuated the inhibition of cell growth and cell death in Au-treated HeLa cells and significantly reduced levels of $\mathrm{O}_{2}^{-}$in these cells. Taken together, Au-induced HeLa cell death was mediated by oxidative stress, mainly derived from $\mathrm{O}_{2}{ }^{-}$.

The Trx system consists of Trx, TrxR and NADPH, which are important for cellular redox balance (1). The present study detected changes in the levels of Trx system-related proteins, revealing that Au decreased the levels of TrxR1 and Trx2. It is possible that the downregulation of Trx 2 affected an increase in the level of $\mathrm{O}_{2}{ }^{-}$in Au-treated HeLa cells, which consequently contributed to the induction of oxidative stress in these cells. GSH is important in protecting against cell damage caused by free radicals and toxins. It can remove $\mathrm{O}_{2}{ }^{--}$and reduce $\mathrm{H}_{2} \mathrm{O}_{2}$ to $\mathrm{H}_{2} \mathrm{O}$ by providing electrons to GSH peroxidase (33). The intracellular GSH content has a crucial effect on cell death $(34,35)$. Similarly, it was demonstrated that $\mathrm{Au}$ increased the number of GSH-depleted cells in the HeLa cells. All the inhibitors assessed, with the exception of Z-LEHD, attenuated the depletion of GSH in the Au-treated HeLa cells and, as expected, NAC markedly prevented the depletion. In addition, BSO significantly increased the depletion of GSH in the Au-treated HeLa cells and simultaneously intensified cell death in these cells. These results suggested that inhibition of the Trx and GSH systems by Au was closely associated with the death of HeLa cells and supports the hypothesis that the inhibition of Trx and GSH systems potentiates the effect of anti-cancer drugs $(36,37)$.

In conclusion, $\mathrm{Au}$ induced the growth inhibition of HeLa cervical cancer cells via apoptosis as well as necrosis, which was accompanied by intracellular increases in the levels of ROS and the depletion of GSH. The present study provides an important insight into the anti-cancer effects of $\mathrm{Au}$ on $\mathrm{HeLa}$ cells with respect to oxidative stress and GSH.

\section{Acknowledgements}

This study was supported by a grant from the National Research Foundation of Korea (NRF) funded by the Korean government (MSIP; no. 2008-0062279) and supported by the Basic Science Research Program through the NRF funded by the Ministry of Education (no. 2013006279).

\section{References}

1. Lu J and Holmgren A: Thioredoxin system in cell death progression. Antioxid Redox Signal 17: 1738-1747, 2012.

2. Collet JF and Messens J: Structure, function, and mechanism of thioredoxin proteins. Antioxid Redox Signal 13: 1205-1216, 2010.

3. Burke-Gaffney A, Callister ME and Nakamura H: Thioredoxin: friend or foe in human disease? Trends Pharmacol Sci 26 398-404, 2005.

4. Rundlöf AK and Arnér ES: Regulation of the mammalian selenoprotein thioredoxin reductase 1 in relation to cellular phenotype, growth, and signaling events. Antioxida Redox Signal 6: 41-52, 2004.

5. Noike T, Miwa S, Soeda J, Kobayashi A and Miyagawa S: Increased expression of thioredoxin-1, vascular endothelial growth factor, and redox factor-1 is associated with poor prognosis in patients with liver metastasis from colorectal cancer. Hum Pathol 39: 201-208, 2008.
6. Karlenius TC, Shah F, Di Trapani G, Clarke FM and Tonissen KF: Cycling hypoxia up-regulates thioredoxin levels in human MDA-MB-231 breast cancer cells. Biochem Biophys Res Commun 419: 350-355, 2012.

7. Fernandes AP, Capitanio A, Selenius M, Brodin O, Rundlöf AK and Björnstedt M: Expression profiles of thioredoxin family proteins in human lung cancer tissue: correlation with proliferation and differentiation. Histopathology 55: 313-320, 2009.

8. Poerschke RL and Moos PJ: Thioredoxin reductase 1 knockdown enhances selenazolidine cytotoxicity in human lung cancer cells via mitochondrial dysfunction. Biochem Pharmacol 81: 211-221, 2011.

9. Fu JN, Li J, Tan Q, et al: Thioredoxin reductase inhibitor ethaselen increases the drug sensitivity of the colon cancer cell line LoVo towards cisplatin via regulation of G1 phase and reversal of G2/M phase arrest. Invest New Drugs 29: 627-636, 2011.

10. Madeira JM, Gibson DL, Kean WF and Klegeris A: The biological activity of auranofin: implications for novel treatment of diseases. Inflammopharmacology 20: 297-306, 2012.

11. Suarez-Almazor ME, Spooner CH, Belseck E and Shea B: Auranofin versus placebo in rheumatoid arthritis. Cochrane Database Syst Rev : CD002048, 2000.

12. Han S, Kim K, Kim H, et al: Auranofin inhibits overproduction of pro-inflammatory cytokines, cyclooxygenase expression and PGE2 production in macrophages. Arch Pharm Res 31: 67-74, 2008.

13. Han S, Kim K, Song Y, et al: Auranofin, an immunosuppressive drug, inhibits MHC class I and MHC class II pathways of antigen presentation in dendritic cells. Arch Pharm Res 31: 370-376, 2008.

14. Liu C, Liu Z, Li M, et al: Enhancement of auranofin-induced apoptosis in MCF-7 human breast cells by selenocystine, a synergistic inhibitor of thioredoxin reductase. PloS One 8: e53945, 2013.

15. Nakaya A, Sagawa M, Muto A, Uchida H, Ikeda Y and Kizaki M: The gold compound auranofin induces apoptosis of human multiple myeloma cells through both down-regulation of STAT3 and inhibition of NF-kappaB activity. Leuk Res 35: 243-249, 2011.

16. Rigobello MP, Scutari G, Boscolo R and Bindoli A: Induction of mitochondrial permeability transition by auranofin, a gold(I)-phosphine derivative. Br J Pharmacol 136: 1162-1168, 2002.

17. Rigobello MP, Folda A, Baldoin MC, Scutari G and Bindoli A: Effect of auranofin on the mitochondrial generation of hydrogen peroxide. Role of thioredoxin reductase. Free Rad Res 39: 687-695, 2005.

18. Haverkos H, Rohrer M and Pickworth W: The cause of invasive cervical cancer could be multifactorial. Biomed Pharmacother 54: 54-59, 2000.

19. De Marco F, Bucaj E, Foppoli C, et al: Oxidative stress in HPV-driven viral carcinogenesis: redox proteomics analysis of HPV-16 dysplastic and neoplastic tissues. PloS One 7: e34366, 2012.

20. Kim NH, Park HJ, Oh MK and Kim IS: Antiproliferative effect of gold(I) compound auranofin through inhibition of STAT3 and telomerase activity in MDA-MB 231 human breast cancer cells. BMB Rep 46: 59-64, 2013.

21. Marzano C, Gandin V, Folda A, Scutari G, Bindoli A and Rigobello MP: Inhibition of thioredoxin reductase by auranofin induces apoptosis in cisplatin-resistant human ovarian cancer cells. Free Rad Biol Med 42: 872-881, 2007.

22. Rigobello MP, Gandin V, Folda A, et al: Treatment of human cancer cells with selenite or tellurite in combination with auranofin enhances cell death due to redox shift. Free Rad Biol Med 47: 710-721, 2009.

23. Han YH, Moon HJ, You BR, Kim SZ, Kim SH and Park WH: Effects of carbonyl cyanide p-(trifluoromethoxy) phenylhydrazone on the growth inhibition in human pulmonary adenocarcinoma Calu-6 cells. Toxicology 265: 101-107, 2009.

24. Han YH, Moon HJ, You BR and Park WH: The effect of MG132, a proteasome inhibitor on HeLa cells in relation to cell growth, reactive oxygen species and GSH. Oncol Rep 22: 215-221, 2009.

25. You BR and Park WH: Zebularine inhibits the growth of HeLa cervical cancer cells via cell cycle arrest and caspase-dependent apoptosis. Mol Biol Rep 39: 9723-9731, 2012.

26. Han YH, Kim SH, Kim SZ and Park WH: Carbonyl cyanide p-(trifluoromethoxy) phenylhydrazone (FCCP) as an $\mathrm{O}_{2}\left({ }^{*}-\right)$ generator induces apoptosis via the depletion of intracellular GSH contents in Calu-6 cells. Lung Cancer 63: 201-209, 2009. 
27. Han YH and Park WH: Propyl gallate inhibits the growth of HeLa cells via regulating intracellular GSH level. Food Chem Toxicol 47: 2531-2538, 2009.

28. You BR and Park WH: Suberoyl bishydroxamic acid-induced apoptosis in HeLa cells via ROS-independent, GSH-dependent manner. Mol Biol Rep 40: 3807-3816, 2013.

29. Martinou JC and Youle RJ: Mitochondria in apoptosis: Bcl-2 family members and mitochondrial dynamics. Dev Cell 21: 92-101, 2011.

30. Niquet J, Allen SG, Baldwin RA and Wasterlain CG: Evidence of caspase-3 activation in hyposmotic stress-induced necrosis. Neurosci Letters 356: 225-227, 2004.

31. Honda A, Abe S, Hiroki E, et al: Activation of caspase 3, 9 , 12 , and $\mathrm{Bax}$ in masseter muscle of $\mathrm{mdx}$ mice during necrosis. J Muscle Res Cell Motil 28: 243-247, 2007.

32. Park SJ and Kim IS: The role of p38 MAPK activation in auranofin-induced apoptosis of human promyelocytic leukaemia HL-60 cells. Br J Pharmacol 146: 506-513, 2005.
33. Hatem E, Berthonaud V, Dardalhon M, et al: Glutathione is essential to preserve nuclear function and cell survival under oxidative stress. Free Radic Biol Med 67: 103-114, 2014.

34. Ortega AL, Mena S and Estrela JM: Glutathione in cancer cell death. Cancers 3: 1285-1310, 2011.

35. Franco R and Cidlowski JA: Glutathione efflux and cell death Antioxid Redox Signal 7: 1694-1713, 2012.

36. Sobhakumari A,Love-Homan L, Fletcher EV, et al: Susceptibility of human head and neck cancer cells to combined inhibition of glutathione and thioredoxin metabolism. PloS One 7: e48175, 2012.

37. Scarbrough PM, Mapuskar KA, Mattson DM, Gius D, Watson WH and Spitz DR: Simultaneous inhibition of glutathione- and thioredoxin-dependent metabolism is necessary to potentiate 17AAG-induced cancer cell killing via oxidative stress. Free Radic Biol Med 52: 436-443, 2012. 